\title{
Fate in intermittent claudication: outcome and risk factors
}

\author{
R JELNES, O GAARDSTING，K HOUGAARD JENSEN， N BæKGAARD， K H TØNNESEN, \\ T SCHROEDER
}

\begin{abstract}
The fate of 257 consecutive patients (100 women) aged $36-85$ years (mean 65) first seen with intermittent claudication in 1977 was analysed after a mean of 6.5 (SD 0.5) years. When first seen none of the patients complained of rest pain or had ulcers or gangrenous lesions on the feet.

At follow up 113 of the patients (44\%) had died. Causes of death were no different from those in the general population. Mortality was twice that of the general population matched for age and sex. Mortality among the men was twice that among the women. In men under 60 mortality was four times that expected.

The rate of clinical progression of the arteriosclerotic disease (that is, rest pain or gangrene) of the worst affected leg was $7 \cdot 5 \%$ in the first year after referral. Thereafter the rate was $2 \cdot 2 \%$ a year. An ankle systolic blood pressure below $70 \mathrm{~mm} \mathrm{Hg}$, a toe systolic blood pressure below $40 \mathrm{~mm} \mathrm{Hg}$, or an ankle/arm pressure index below $\mathbf{5 0 \%}$ were individually significantly associated with progression of the arteriosclerotic disease.
\end{abstract}

These findings show the importance of peripheral blood pressure measurements in the management of patients with intermittent claudication due to arteriosclerotic disease.

\section{Introduction}

Reconstructive vascular surgery for obliterating arterial disease in the legs has been routine for decades. The selection of patients for arterial reconstruction, however, appears to be ill defined in one category of patients-namely, those complaining solely of intermittent claudication. This is due to the known benign spontaneous course of the disease and the fact that reconstructive vascular surgery entails a small but definite risk of early amputation $(0-2 \%)$ and death $(0-3 \%)$.

Exercise and stopping smoking have been shown to be the best conservation treatment in these patients in terms of improved walking ability and reduction of adverse events. ${ }^{2-6}$

Little has been reported on the clinical course of intermittent claudication. ${ }^{7.9}$ Bloor in 1961 found that patients with arteriosclerosis had a life expectancy similar to that of a healthy population 10 years older. ${ }^{10}$ The yearly risk of pregangrene and gangrene was reported to be $5 \%$ in the first five years after referral. Data for the study were collected during the late 1940s and early 1950s.

The purpose of our study was to elucidate the outcome and risk factors in patients first seen with intermittent claudication in the 1970s. Special attention was paid to clinical progression of the peripheral arteriosclerotic disease leading to ischaemic rest pain or gangrene and death, as well as to defining any risk factors in the patient population.

\footnotetext{
Department of Clinical Physiology/Nuclear Medicine, Department of Surgery M, Bispebjerg Hospital, Bispebjerg Bakke 23, DK-2400 Copenhagen NV, Denmark

R JELNES, MD, senior registrar

O GAARDSTING, $M D$, registrar

K HOUGAARD JENSEN, MD, registrar

N BÆKGAARD, MD, senior registrar

K H TONNESEN, MD, chief physician

T SCHROEDER, MD, senior registrar

Correspondence and requests for reprints to: Dr Jelnes.
}

\section{Patients and methods}

The study comprised 257 patients referred consecutively and for the first time to the department of clinical physiology at Bispebjerg Hospital in 1977 for intermittent claudication. " The mean age of the patients (100 women, 157 men) was 65 (SD 8.8) years (range 36-85) and there was no sex difference.

None of the patients had previously attended hospital for their arterial insufficiency and none complained of rest pain or had ulcers or gangrenous lesions on the feet. The patients came from all social classes, and all grades of severity of claudication were represented.

On referral a detailed medical history was obtained. Fourteen patients $(5 \cdot 4 \%)$ had a history of treatment for diabetes.

The diagnosis of intermittent claudication was based on the history, clinical examination, and systemic and peripheral blood pressures. The diagnosis was further established by treadmill exercise $(2 \mathrm{mph}(3.2 \mathrm{~km} / \mathrm{h})$ at 8 degrees of elevation) in those able to collaborate with this test.

Systemic blood pressure was measured by auscultation using a standard cuff $(12$ by $35 \mathrm{~cm})$ and a mercury manometer with blind zero (Hawksley, United Kingdom). Diastolic blood pressure was recorded at the disappearance of the Korotkoff sounds. Mean arterial blood pressure was calculated as the diastolic blood pressure plus one third of the pulse amplitude.

Systolic blood pressure at the ankle and in the first toe was measured by the strain gauge technique. ${ }^{12}$ The ankle/arm systolic blood pressure index was calculated. Other studies have found toe systolic blood pressure to be of prognostic value in regard to healing of ulcers. ${ }^{1314}$ Table I shows the peripheral pressures of the patient population. Forty four patients $(17 \%)$ had a toe systolic blood pressure below $30 \mathrm{~mm} \mathrm{Hg}$.

The quality of the pulsation in the common femoral artery was noted by palpation (normal, diminished, or absent). Normal pulsation was found in 186 patients $(72 \%)$, indicating femoropopliteal-crural disease. Absent or

TABLE I-Ankle systolic blood pressure, ankle/arm systolic blood pressure index, and toe systolic blood pressure of patient population $(n=257)$

\begin{tabular}{lrrc}
\hline & Mean & SD & Range \\
\hline Ankle systolic blood pressure (mm Hg) & 83 & 24 & $33-208$ \\
Ankle/arm systolic blood pressure index & 0.54 & $0 \cdot 16$ & $0 \cdot 21-1 \cdot 03$ \\
Toe systolic blood pressure $(\mathrm{mm} \mathrm{Hg})$ & 50 & 20 & $9-105$ \\
\hline
\end{tabular}

diminished pulsations in the groin were found in 71 patients $(28 \%)$, indicating at least aortoiliac disease.

As it was the policy of the institution to carry out vascular reconstructions only for limb salvage-that is, only in patients with pain at rest or gangrene-patients in this study continued with conservative management unless disease progression occurred. Hence the analysis of events described below may be taken as an analysis of disease progression as such. Patients were encouraged to give up smoking and to make great efforts to exercise. Further care in this aspect was not undertaken in the observation period.

Follow up was carried out during April 1983 to May 1985. A total of 113 $(44 \%)$ of the patients had died. Of the remaining 144 patients (mean follow up $6.5(\mathrm{SD} 0.5)$ years), 134 were interviewed especially in regard to reconstructive vascular surgery, amputations, and smoking habits. Information on the patients who had died was obtained from hospital records and death certificates. Ten patients who were known to be alive at follow up had moved to another area and could not be contacted. The hospital records of these patients were searched for information on reconstructive vascular surgery and amputations.

Statistical methods-Only data concerning the leg which according to the patients was worse affected in 1977 were considered for statistical analysis. Data concerning death and clinical progression of the peripheral arteriosclerotic disease leading to reconstructive vascular surgery or amputation were cumulated by life table analysis. Comparison of outcome in subgroups 
was performed with the log rank test. ${ }^{15}$ The Cox regression model ${ }^{16}$ was used for testing the association between death and clinical progression on the one hand and the prognostic variables on the other. The selected prognostic variables included age, sex, ankle systolic blood pressure, toe systolic blood pressure, diabetes mellitus, mean arterial blood pressure, and the character of the pulsation in the common femoral artery. The impact of a given variable on the interpatient risk variability is proportional to its risk increasing effect but also to its own variation in the patient population. Figures in the "Impact" columns of tables II and V are the factors by which the risk increased when the variable was changed from the 25th to the 75th percentile of the sample at hand. For binary variables such as sex this was calculated in a comparable manner. Frequency data were compared by the $\chi^{2}$ test; $\mathrm{p}<0.05$ was considered significant.

\section{Results}

\section{RECONSTRUCTIVE VASCULAR SURGERY AND AMPUTATIONS}

During the observation period 42 patients developed ischaemic rest pain or gangrene due to progression of the arteriosclerotic disease. Twenty four of these had reconstructive vascular surgery while 18 had legs primarily amputated. Figure 1 shows the cumulative incidence of disease progression. Data suggest a curve consisting of two parts-namely, an incidence of $7.5 \%$ during the first year followed by a yearly rate of $2 \cdot 2 \%$ in subsequent years. At five years the cumulative rate of reconstructive vascular surgery was $9 \cdot 5 \%$ and the cumulative amputation rate $6 \cdot 8 \%$.

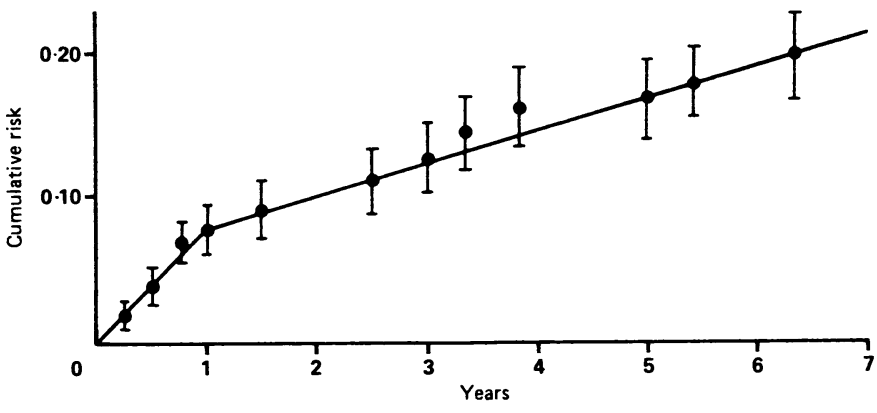

FIG 1-Mean cumulative risk of clinical progression of arteriosclerotic disease leading to rest pain or gangrene. Bars are SD.

Table II gives the results of risk factor analysis in relation to clinical progression of the disease. Ankle systolic blood pressure seemed to be a highly significant predictor for clinical progression. The purpose of the Cox analysis was to elucidate the simultaneous predictive power of the variables, so not surprisingly toe systolic blood pressure-which was a prognostic factor when considered in isolation-did not come out significantly in the simultaneous analysis. The reason is that ankle systolic blood pressure conveys the same prognostic information. Table III shows the frequencies of disease progression in patients with values below various cut off points and in the total sample. An ankle systolic blood pressure below $70 \mathrm{~mm} \mathrm{Hg}$, a toe systolic blood pressure below $40 \mathrm{~mm} \mathrm{Hg}$, or an ankle/arm systolic blood

TABLE II-Risk factors entering into instantaneous net risk of clinical progression of arteriosclerotic disease leading to rest pain or gangrene ${ }^{\star}(n=257)$

\begin{tabular}{|c|c|c|c|c|}
\hline & Risk factor & $\begin{array}{l}\text { Approximate } 95 \% \\
\text { confidence interval for } \\
\text { risk factor }\end{array}$ & Impact & $\begin{array}{l}\text { Two sided } \\
\text { statistical } \\
\text { significance }\end{array}$ \\
\hline Age & (1) & & (1) & NS \\
\hline Male sex & 0.65 & $0 \cdot 34$ to $1 \cdot 26$ & $1 \cdot 32$ & $p=0.20$ \\
\hline Ankle systolic blood pressure, a & $a-2 \cdot 43$ & $a-3.48$ to $a-1.39$ & $2 \cdot 65$ & $\mathrm{p}<0.00001$ \\
\hline Diabetes mellitus & $2 \cdot 02$ & 0.59 to 6.96 & $1 \cdot 24$ & $p=0.27$ \\
\hline Mean arterial blood pressure & $1.33 t$ & 1.07 to 1.65 & $1 \cdot 74$ & $\mathrm{p}=0.01$ \\
\hline Men & $1 \cdot 16 \dagger$ & & & \\
\hline Women & $1.62 \dagger$ & & & \\
\hline Pulsation in groin & (1) & & (1) & NS \\
\hline Toe systolic blood pressure $\ddagger$ & (1) & & (1) & NS \\
\hline
\end{tabular}

*Net risk refers to risk of not avoiding surgery owing either to death or to a favourable course and thus reflects surgical workload.

tFactor by which risk increased for $10 \mathrm{~mm} \mathrm{Hg}$ in mean arterial blood pressure łSee statistical section.
TABLE III-Frequency of progression of arteriosclerotic disease related to ankle and toe systolic blood pressures and to ankle systolic blood presssure index. Results expressed as number (percentage) of patients.

\begin{tabular}{|c|c|c|}
\hline $\begin{array}{l}\text { Cut off } \\
\text { value }\end{array}$ & $\begin{array}{c}\text { Frequency } \\
\text { (total } 42: 257(16) \text { ) }\end{array}$ & Significance* \\
\hline \multicolumn{3}{|c|}{ Ankle systolic blood pressure $(\mathrm{mm} \mathrm{Hg}$ ) } \\
\hline $\begin{array}{l}<100 \\
<90 \\
<80 \\
<70 \\
<60 \\
<50\end{array}$ & $\begin{array}{c}35 / 203(17) \\
31 / 159(19) \\
24 / 115(21) \\
17 / 70(24) \\
11 / 38(29) \\
10 / 21(48)\end{array}$ & $\begin{array}{c}p=0.053 \\
p=0.031 \\
p=0.027 \\
p<0.00001\end{array}$ \\
\hline \multicolumn{3}{|c|}{ Toe systolic blood pressure $(\mathrm{mm} \mathrm{Hg})$} \\
\hline $\begin{array}{l}<60 \\
<50 \\
<40 \\
<30\end{array}$ & $\begin{array}{c}36 / 174(21) \\
25 / 131(19) \\
19 / 84(23) \\
16 / 44(36)\end{array}$ & $\begin{array}{c}\mathrm{p}=0.16 \\
\mathrm{p}=0.048 \\
\mathrm{p}<0.00001\end{array}$ \\
\hline \multicolumn{3}{|c|}{ Ankle/arm systolic blood pressure index (\%) } \\
\hline $\begin{array}{l}<70 \\
<60 \\
<50 \\
<40 \\
<30\end{array}$ & $\begin{array}{c}36 / 213(17) \\
32 / 173(18) \\
25 / 100(25) \\
16 / 41(39) \\
7 / 16(44)\end{array}$ & $\begin{array}{l}p=0.285 \\
p=0 \cdot 10 \\
p=0.002 \\
p<0 \cdot 00001\end{array}$ \\
\hline
\end{tabular}

${ }^{\star} p$ Values based on $\chi^{2}$ tests comparing patients with values above and below cut off point.

pressure index below $50 \%$ were individually significantly associated with o progression of the arteriosclerotic disease.

No patient with an ankle pressure above $70 \mathrm{~mm} \mathrm{Hg}$ in $1977 \mathrm{had}$ an amputation during the observation period.

Mean arterial blood pressure also was found to be a significant predictor, $\omega$ the risk increasing by 1.33 for each $10 \mathrm{~mm} \mathrm{Hg}$ rise in pressure. This implies 음 an increase of ankle systolic blood pressure but a lowering of the ankle/arm systolic blood pressure index.

Age, sex, diabetes, and the nature of the pulsation in the groin came out as non-significant predictors (table II)

\section{MORTALITY}

During the observation period 113 patients (44\%) died (table IV), four of them $(4 \%)$ of ruptured aortic aneurysms $(95 \%$ confidence interval 1 to $9 \%)$. The cumulative five year mortality was $31 \%$ (SD 2.9\%). Mortality was twice the expected compared with an age and sex matched population (fig 2).

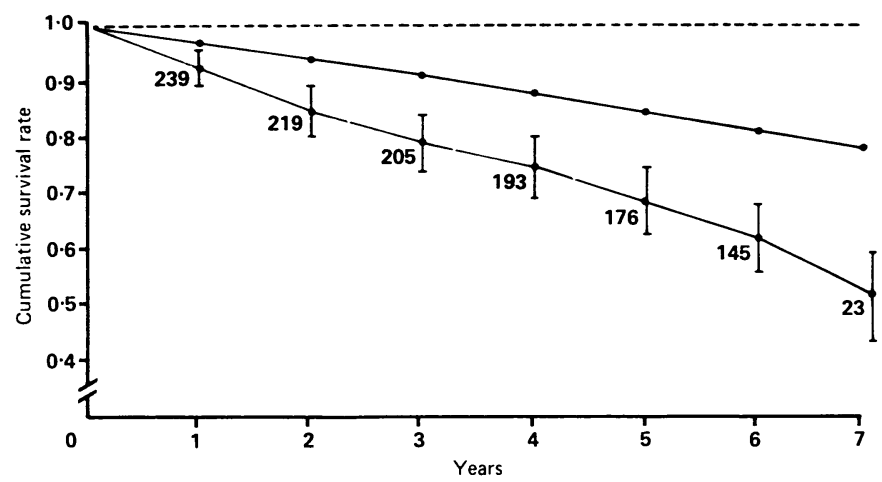

FIG 2-Mean cumulative survival rate of patient population compared with age and sex matched population. Bars are 2 SD.

( (1/24) for reconstructive vascular surgery and $44 \%(8 / 18)$ for amputations.

Table $\mathrm{V}$ gives the results of risk factor analysis in relation to death.? Mortality among the men was roughly twice that among the women $\square$ $\left(p=0.0014\right.$; fig 3). Men below the age of 60 at referral $(49 / 157)$ had a death ${ }^{\circ}$ rate four times the expected, whereas in men over $60(108 / 157)$ the death rate $\mathbb{D}$ was twice the expected-that is, similar to that of the patient population as a $\overrightarrow{\mathbb{\Phi}}$ whole.

Peripheral pressures (illustrated by ankle systolic blood pressure in table V) were significant predictors for death. The risk was estimated to double 8 when ankle systolic blood pressure fell from $105 \mathrm{~mm} \mathrm{Hg}$ to $45 \mathrm{~mm} \mathrm{Hg}$ and to응 double again when it fell to $20 \mathrm{~mm} \mathrm{Hg}$. 
Hypertensive patients (those with a mean arterial blood pressure over 120 $\mathrm{mm} \mathrm{Hg}$ ) were also found to be at risk in this study. The risk factor was calculated as 1.32 for each $10 \mathrm{~mm} \mathrm{Hg}$ that the mean arterial blood pressure exceeded $120 \mathrm{~mm} \mathrm{Hg}$.

Diabetes did not come out as a significant predictor for death. As expected, age came out as the most significant predictor for death.

\section{SMOKING HABITS}

Of the 144 patients who were alive at follow up, $130(90 \%)$ were smokers in 1977 . Only $19(15 \%)$ of these patients had given up smoking despite having been told that this might diminish the risk of losing their leg. low pressure vascular bed had a considerably higher risk of reconstructive vascular surgery or amputation. Interestingly, none of the patients with an ankle systolic blood pressure above $70 \mathrm{~mm}$ $\mathrm{Hg}$ at the first visit had an amputation during the observation period.

Absence of palpable pulsation in the groin was of no predictive value, which contrasts with the findings of Bloor. ${ }^{10}$ This may be related to aortofemoral bypass grafting, which nowadays is offered more readily to patients previously considered to be at a high operative risk. This is due to the great improvements in peroperative and postoperative monitoring.

Patients with a low pressure vascular bed should thus be

TABLE IV-Causes of death in patients with intermittent claudication

\begin{tabular}{lcccccccc}
\hline & Cardiac & Malignancy & Cerebral & $\begin{array}{c}\text { Pulmonary } \\
\text { embolism }\end{array}$ & $\begin{array}{c}\text { Ruptured } \\
\text { aortic } \\
\text { aneurysm }\end{array}$ & $\begin{array}{c}\text { Miscel- } \\
\text { laneous }\end{array}$ & Unknown & Total \\
\hline No(\%) of patients & $51(45)$ & $27(24)$ & $11(10)$ & $7(6)$ & $4(4)$ & $5(4)$ & $8(7)$ & $113(100)$ \\
\hline
\end{tabular}

TABLE V-Factors entering instantaneous risk of death $(n=257)$

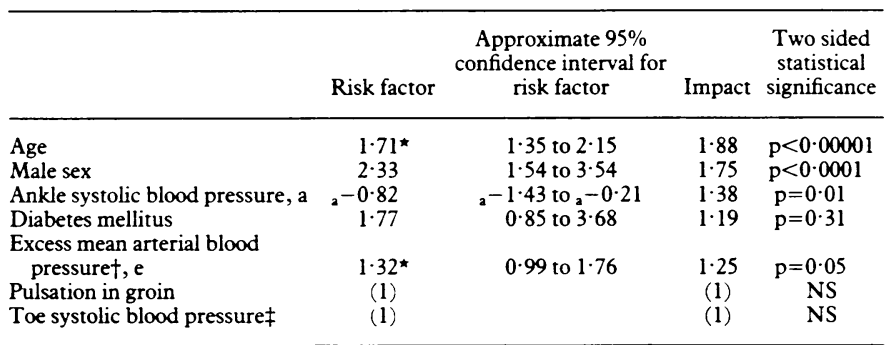

^Factor by which risk increased for each 10 years or $10 \mathrm{~mm} \mathrm{Hg}$

$\mathrm{te}=\operatorname{Maximum}(0$, mean arterial blood pressure- $120 \mathrm{~mm} \mathrm{Hg})$.

†See statistical section.

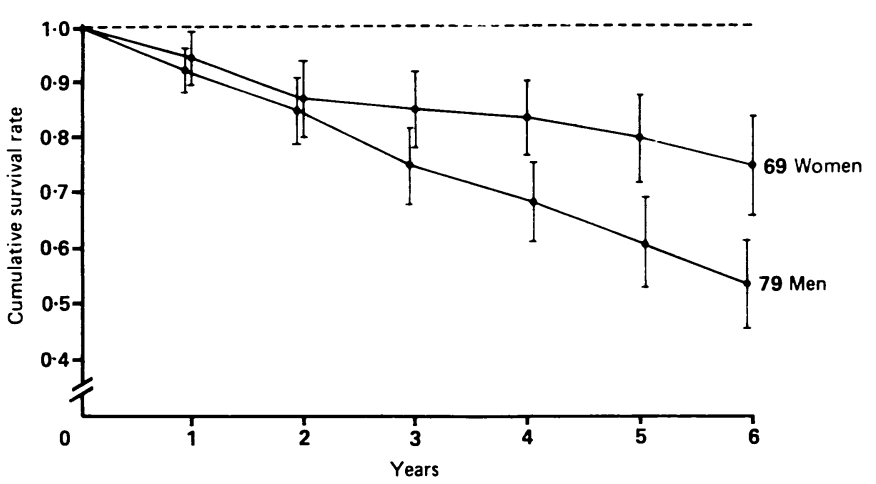

FIG 3-Mean cumulative survival rate of women and men in patient population. Bars are $2 \mathrm{SD}$.

\section{Discussion}

The rate of progression of the arteriosclerotic disease was three times higher during the first year after referral than in subsequent years $(7 \cdot 5 \% \vee 2 \cdot 2 \%$; fig 1$)$, corroborating the $8.3 \%$ and $3.0 \%$, respectively, reported by Bloor. ${ }^{10}$ The high risk during the first year may be explained by the facts that patients seek help after a period of deterioration and that a sufficient collateral circulation takes time to develop.

Our study shows the prognostic value of ankle and toe systolic blood pressure measurements. An ankle systolic blood pressure below $70 \mathrm{~mm} \mathrm{Hg}$, toe systolic blood pressure below $40 \mathrm{~mm} \mathrm{Hg}$, or an ankle/arm systolic blood pressure index below $50 \%$ were predictive of disease progression (table III). Hence patients with a controlled carefully, especially during the first year after referral.

Our finding of a death rate twice that of the general population (fig 2) may be an overestimate. Mortality was influenced by the nine operative deaths and, in addition, patients aged 60-70 in the Copenhagen area have a mortality $24 \%$ higher than the average Danish population. ${ }^{17}$ The five year cumulative survival rate of $69 \%$ compared with $85 \%$ for the age and sex matched population nevertheless confirms that intermittent claudication is associated with a high mortality. In our series this was most pronounced in men under 60.

A comparatively large number of patients $(5 / 113 ; 4 \%)$ died of ruptured aortic aneurisms, which agrees with other reports. ${ }^{510}$

Patients with hypertension should have their mean arterial blood pressure kept below $120 \mathrm{~mm} \mathrm{Hg}$, as their risk of dying increases significantly above this level. In controlled studies $\beta$ blocking agents given to hypertensive patients with claudication have not been associated with any detrimental effects on peripheral blood pressure or walking distance. ${ }^{1820}$

The number of patients with diabetes mellitus and its nonsignificant influence on adverse events were similar to the findings of Bloor. ${ }^{10}$ Large epidemiological studies, however, have shown a higher mortality in diabetics ${ }^{21}$ as well as a greater risk of developing rest pain or gangrene. ${ }^{22}$ In our study only $14(5.4 \%)$ of the patients were diabetic compared with $20-30 \%$ of patients with rest pain and gangrene in a previous series. ${ }^{11}$ This suggests that many patients with diabetic gangrene do not have the in between symptom of intermittent claudication.

The male to female ratio has changed dramatically since the 1950s. A ratio of 10:1 was reported around $1960,{ }^{69}$ and this has gradually diminished. ${ }^{6923}$ In our study the ratio was $1 \cdot 6: 1$. The most probable explanation is the increased smoking by women that occurred during the social and economic liberation after the second world war. The vast majority of our patients were smokers. The strong association between smoking and arteriosclerosis is well documented. ${ }^{24} 26$

In conclusion, our study shows the prognostic importance of patients with intermittent claudication having their ankle blood pressure measured at the first examination. If the ankle systolic blood pressure is below $70 \mathrm{~mm} \mathrm{Hg}$ the patient should be controlled carefully during the first year after referral. At the same time patients should be referred to supervised exercise classes, ${ }^{27}$ especially if the ankle/arm systolic blood pressure index is less than $50 \% .^{28}$ They should abstain from smoking ${ }^{4}$ and have their blood pressure controlled. When the indications for surgery are fulfilled arteriography should be performed in preparation for interventions on the arterial tree.

We thank the Danish Medical Research Council for statistical advice (grant No 5.52.15.48). 
16 Cox DR. Regression models and life-tables. Fournal of the Royal Statistics Society, Series $B$ 1972;34:187-220.
(1)

1 Barker VF. Periphe 1975:220-53

NA. Effect of daily muscular exercise in patients with intermittent claudication. Lancet 1966;: 1093-5.

3 Ericsson B, Haeger K, Lindell SE. Effect of physical training on intermittent claudication. Angiology 1979;21:188-92.

4 Quick CRG, Cotton LT. The measured effect of stopping smoking on intermittent claudication. Brf Surg 1982;69(suppl):S24-6.

5 Hughson WG, Mann JI, Tibbs DJ, Woods HF, Walton I. Intermittent claudication: factor determining outcome. BrMed $\mathcal{F} 1978 ;$ i: $1377-9$.

6 Mathiesen FR, Errebo Larsen E, Wulff M. Some factors influencing the spontaneous course of arterial insufficiency. Acta Chir Scand 1970;136:303-8.

7 Juergens JL, Barker NW, Hines EA. Arteriosclerosis obliterans: review of 520 cases with special reference to pathogenic and prognostic factors. Circulation 1960;21:188-95.

8 Imparato AM, Kim G-E, Davidson T, Crowley JG. Intermittent claudication: its natural course. Surgeny 1975;78:795-9.

9 McAllister FF. The fate of patients with intermittent claudication managed nonoperatively.

10 Bloor K. Natural history of arteriosclerosis of the lower extremities. Ann R Coll Surg Engl $1961 ; 28: 36-52$

11 Tonnesen KH, Noer I, Paaske W, Sager Ph. Classification of peripheral occlusive diseases based on symptoms, signs and distal blood pressure measurements. Acta Chir Scand 1980;146:101-4. 12 Strandness DE, Bell JW. Peripheral vascular disease: diagnosis and objective evaluation using mercury strain gauge. Ann Surg 1965;161:3-32.

13 Holstein P, Lassen NA. Healing of ulcers on the feet correlated with distal blood pressure measurements in occlusive arterial disease. Acta Orthop Scand 1980;51:995-1006.

14 Ramsey DE, Manke DA, Sumner DS. Toe blood pressure. A valuable adjunct to ankle pressure measurement for assessing peripheral arterial disease. $\mathcal{f}$ Cardiovasc Surg 1983;24:43-8.

15 Peto R, Pibe MC, Armitage P, et al. Design and analysis of randomized clinical trials requiring prolonged observation of each patient. II. Analysis and examples. Br f Cancer 1977;35:1-39.
Horwitz N, Dalgaard OZ. Dodelighedsforskelle som indikator for uensartet sundhedstilstand fra amt til amt. Ugeskr Laeger 1985;147:2105-13.

18 Bogaert MG Clement DL. Lack of influence of propranolol and metoprolol on walking distance in $\widehat{\Omega}$ patients with chronic intermittent claudication. Eur Heart 7 1983;4:203-4 chronic antihypertensive treatment with metoprolol and methyldopa. Clin Physiol 1984;4: ग] $275-82$

20 Svendsen TL, Jeines R. Tonnesen $\mathrm{KH}$. The effects of acebutolol and metoprolol on walking $\Pi$ distances and distal blood pressure in hypertensive patients with intermittent claudication. Acta $\varrho$ Med Scand 1986;219:161-5.

21 Jarrett RJ, Keen H, Chakrabarti R. Diabetes, hyperglycaemia and arterial disease. In: Keen $\mathrm{H}, \overrightarrow{\overline{\vec{F}}}$ Jarrett RJ, eds. Complications of diabetes. 2nd ed. London: Edward Arnold Ltd, 1982:180-2.

22 Jonason T, Ringqvist I. Diabetes mellitus and intermittent claudication. Actu Med Scand 1985;218:217-21

23 Reunanen A, Takkunen H, Aromaa A. Prevalence of intermittent claudication and its effect on

mortality. Acta Med Scand 1982;211:249-56.
24 Kannel WB, Shurtieff D. Cigarettes and the development of intermittent claudication-the $\frac{\text { D }}{\overparen{D}}$ Framingham study. Geriatrics 1973;28:61-8. 25 Hughson WG, Mann JI, Garrod A. Intermittent claudication: prevalence and risk factors.

26 US Department of Health and Human Services. The health consequences of smoking. A report of the $\vec{O}$ Surgeon General. Bethesda, Md: National Institutes of Health, 1983:182-6.

27 Clifford PC, Davies PW, Hayne JA, Baird RN. Intermittent claudication: is a supervised exercise $\vec{\sim}$ class worth while? BrMed f 1980;280: 1503-5.

28 Rosetzsky A, Struckmann J, Mathiesen FR. Minimal walking distance following exercise of treatment in patients with arterial occlusive disease. Ann Chir Gynaecol 1984;74:261-4.

(Accepted 5 August 1986)

\title{
Assessment of non-mydriatic fundus photography in detection of diabetic retinopathy
}

\author{
ROBERT WILLIAMS, STEPHEN NUSSEY, ROGER HUMPHRY, GRAHAM THOMPSON
}

\begin{abstract}
Non-mydriatic retinal photography with later interpretation of the photographs was assessed as a screening method for the detection of diabetic retinopathy; when compared with an ophthalmologist's clinical assessment in a random group of $\mathbf{6 2}$ diabetic patients it was accurate (false negative $6.8 \%$, false positive $2 \%$ ) and sensitive (sensitivity $96 \%$, specificity $98 \%$ ). The assessment of further management required based on analysis of the photographs was $96.5 \%$ in agreement with the further management suggested by the ophthalmologist after direct clinical assessment of the patient.
\end{abstract}

If this technique were used to screen patients in a typical diabetic clinic the predicted positive accuracy rate would be $84 \%$ and the predicted negative accuracy rate $99.5 \%$.

\section{Introduction}

Diabetic eye disease is the commonest cause of blindness in people of working age ${ }^{12}$ despite the widespread availability of effective photocoagulation treatment. ${ }^{34}$ Many diabetics are not regularly screened for treatable eye disease and present with advanced

St George's Hospital, London SW17

ROBERT WILLIAMS, MRCP, FRCS, senior registrar, ophthalmic unit STEPHEN NUSSEY, MRCP, Wellcome lecturer, diabetic unit

ROGER HUMPHRY, FRCS, registrar, ophthalmic unit

GRAHAM THOMPSON, FRCS, consultant ophthalmologist, ophthalmic unit

Correspondence to: Mr Williams, Worthing Hospital, Worthing, West Sussex BN11 2DH disease, for which treatment is difficult, expensive, and lessड effective. Screening has been shown to be cost effective, ${ }^{5}$ but thereo are insufficient ophthalmologists to screen all diabetics. ' Currently, screening is mainly by fundal examination performed by medical $\mathbb{Q}$ staff, which is expensive and has been shown to be inaccurate. $\overrightarrow{0}$ There is an urgent need for a cheaper screening method that does 3 not need to be performed by specialists in ophthalmology.

Non-mydriatic retinal photography, a recently developed tech nique, has been reported as a method of recording the fundas appearance. ${ }^{9}$ Although it has been compared with standard $30^{\circ}$ stereophotography and direct ophthalmoscopy by a technician: through an undilated pupil, ${ }^{10}$ it has not been compared with an ophthalmologist's assessment. We assessed non-mydriatic retinah photography as a means of detecting diabetic retinopathy and compared the results with those obtained by direct examination by an ophthalmologist and a doctor with an interest in diabetes.

\section{Patients and methods}

The protocol was approved by the ethical committee. Patients werf selected at random from those attending a general diabetic clinic and a diabetic eye disease clinic. After giving informed consent they were assesseck in three ways. Firstly, the patients' fundi were examined by the doctor (thi\& was his usual screening practice in the diabetic clinic), and their pupils were dilated. Secondly, single retinal photographs were taken of each eye through ${ }^{+}$ the undilated pupil using either the Kowa or the Canon CR3 non-mydriatic fundus cameras with either Polaroid 600 colour prints film or Kodachrome ASA 200 colour transparency film. Both cameras photograph around $45^{\circ}$ of the fundus, and they were positioned so that the area photographed exten $\mathbb{\Omega}$ ded from just nasal to the optic disc to temporal to the macula. The photographs were assessed by two ophthalmologists after all the patients had been studied. Finally, the patients' fundi were examined through dilated pupilo by an ophthalmologist, using both direct and indirect ophthalmoscopy.

Both examinations and the photographic interpretation were undertaket. 